Research Article

\title{
Interface Shear Actions and Mechanical Properties of Nanostructured Dissimilar Al Alloy Laminated Metal Composites
}

\author{
Zejun Chen ${ }^{1,2}$ and Quanzhong Chen ${ }^{3}$ \\ ${ }^{1}$ State Key Laboratory of Mechanical Transmission, College of Materials Science and Engineering, Chongqing University, \\ Chongqing 400044, China \\ ${ }^{2}$ State Key Laboratory of Metastable Materials Science and Technology, Yanshan University, Qinhuangdao, Hebei 066004, China \\ ${ }^{3}$ WISDRI Engineering and Research Incorporation Limited, Wuhan, Hubei 430223, China
}

Correspondence should be addressed to Zejun Chen; zjchen@cqu.edu.cn

Received 20 June 2015; Revised 30 August 2015; Accepted 5 October 2015

Academic Editor: Hanadi Salem

Copyright ( 2015 Z. Chen and Q. Chen. This is an open access article distributed under the Creative Commons Attribution License, which permits unrestricted use, distribution, and reproduction in any medium, provided the original work is properly cited.

\begin{abstract}
The laminated metal composites (LMCs) of dissimilar metals (aluminium alloys: AA1100/AA7075) were fabricated using the accumulative roll bonding technique in conjunction with cold rolling. The LMCs of ultrafine grained AAl100 and nanostructured precipitates of AA7075 achieved metallurgical bonding. The microstructure of the bonding interfaces and constituent metals was investigated using scanning electron microscopy and transmission electron microscopy for the LMCs with different layers. The deformation incompatibility and shear actions were analyzed using the microanalysis of dissimilar bonding interfaces. The mechanism of grain refinement of LMCs was investigated and described based on the microstructure characterization. The mechanical properties, strengthening mechanism, and fracture mechanism of LMCs were also investigated. The research results showed that the strengthening mechanism of LMCs is the recombination action of grain refinement, dislocation, and laminated interfacial strengthening. The coordinated deformation of dissimilar metals and the layer thickness are important in improving the mechanical properties of LMCs consisting of dissimilar metals.
\end{abstract}

\section{Introduction}

Ultrafine grained (UFG) materials include both submicrocrystalline materials with grain sizes in the range of 100$1000 \mathrm{~nm}$ and nanocrystalline materials with grain sizes below $100 \mathrm{~nm}$. Such materials usually have superior mechanical and physical properties, including high strength, improved corrosion resistance, and higher wear resistance, which are very different from the same materials comprising conventionally sized grains [1-5]. Therefore, the field of UFG materials remains one of the hot topics in the field of materials science and engineering. Two complementary approaches have been developed for synthesizing UFG materials. The first is the "bottom-up" approach in which UFG materials are assembled from individual atoms or from nanoscale building blocks such as nanoparticles. The bottom-up process to obtain theoretical dense materials is the pulsed electrodeposition method, which yields nanocrystalline strips; however, these strips only have thicknesses of several hundred microns $[6,7]$. The second is the "top-down" approach in which existing coarse grained materials are processed to produce ultrafine grains. The most successful top-down approaches involve the application of severe plastic deformation (SPD) [2, 5, 8-10], in which materials are subjected to the imposition of strains that are typically larger than 4-6. A unique feature of SPD processing is that the high strain is imposed without any significant change in the overall dimensions of the sample $[2,5]$. The SPD approach starts with conventional crystalline microstructured metals and alloys, and defects such as dislocations and point defects are introduced by extreme strains on the precursor materials. The recrystallization of the material leads to finer and finer grain sizes and under 


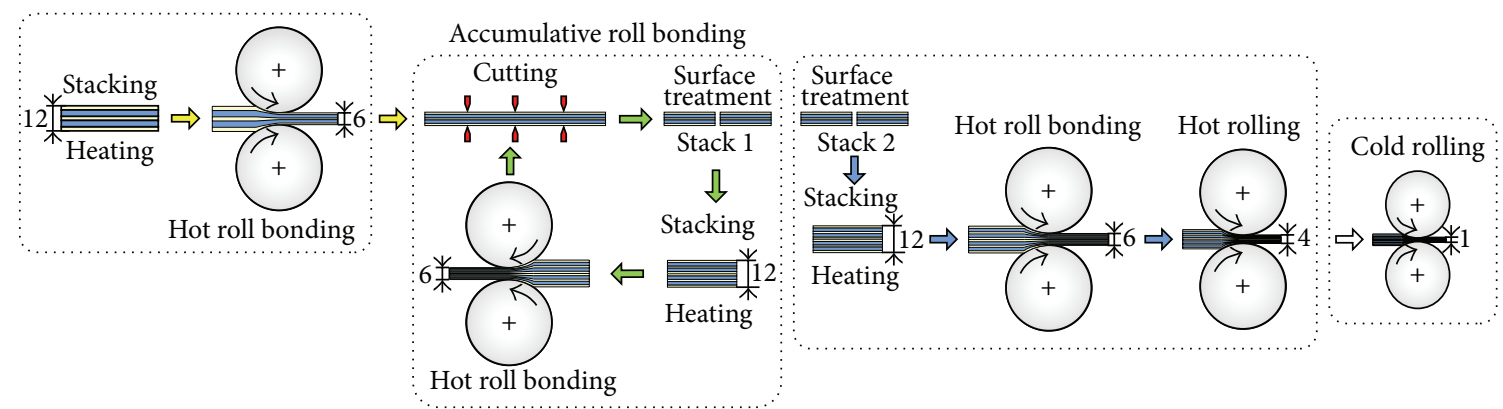

FIgURE 1: Schematic diagram for fabricating the nanostructured $\mathrm{Al}$ alloys LMCs (mm).

certain processing conditions to nanostructured materials. A unique feature of SPD processing is that a high strain is imposed without any significant change in the overall dimensions of the sample [2]. Various SPD processes such as high pressure torsion (HPT) [1], equal channel angular pressing (ECAP) $[3,11]$, accumulative roll bonding (ARB) $[12,13]$, repetitive corrugation and straightening (RCS) [14], torsion extrusion [15], cyclic extrusion compression (CEC) [16], severe torsion straining (STS) [17], super short multipass rolling (SSMR) [18], cyclic closed-die forging (CCDF) [19], and other new methods [20] have been developed. When all the approaches in use for the production of nanostructured materials are examined, only the SPD processes show potential for producing relatively large samples suitable for industrial applications. Among the SPD methods $[2,5,8-$ $10]$, the ARB method $[12,13]$ obviously exceeds others for its high efficiency, high speed, and continuous working. ARB has the benefit that it does not require specialized equipment or tooling, only a conventional rolling mill.

ARB is one of the important severe plastic deformation (SPD) processes. It is a method of rolling a stack of metal sheets, which is repeatedly rolled to give a severe reduction ratio, and then dividing the stack into two halves, placing one pile on the other and then rolling it again. The surfaces to be joined must be cleaned well before rolling to ensure good bonding. It has often been proposed as a method for the production of metal materials with UFG microstructure. The earliest research on ARB was by Saito and coworkers $[12,13]$. To obtain a single slab of a solid material, the rolling involved not only deformation, but also roll bonding [21]. Recently, more and more studies have been focused on UFG laminated metal composites (LMCs) consisting of bimetal systems fabricated by ARB, such as aluminium/aluminium (scandium) $[\mathrm{Al} / \mathrm{Al}(\mathrm{Sc})][22]$, aluminium/copper $(\mathrm{Al} / \mathrm{Cu})$ [23], aluminium/nickel $(\mathrm{Al} / \mathrm{Ni})$ [24, 25], aluminium/zinc ( $\mathrm{Al} / \mathrm{Zn})$ [26], titanium/aluminium (Ti/Al) [27-29], copper/zirconium $(\mathrm{Cu} / \mathrm{Zr})$ [30], $\mathrm{Cu} / \mathrm{Ni}$ [31], aluminium/magnesium (Al/Mg) [32-36], Al/Al alloy [3742], $\mathrm{Al} /$ steel [43], copper/niobium ( $\mathrm{Cu} / \mathrm{Nb})$ [44], and zirconium/niobium ( $\mathrm{Zr} / \mathrm{Nb})$ [45]. There are even some LMCs fabricated by ARB using three or more metal systems [46, 47]. It is observed that more efforts are focused on the area of LMCs consisting of dissimilar metals with ultrafine or nanostructured grains. However, the scientific community still faces some important issues, including improving fatigue
TABLE 1: Chemical compositions of AA1100 and AA7075 (mass\%).

\begin{tabular}{lccccccccc}
\hline & $\mathrm{Zn}$ & $\mathrm{Mg}$ & $\mathrm{Cu}$ & $\mathrm{Si}$ & $\mathrm{Fe}$ & $\mathrm{Mn}$ & $\mathrm{Cr}$ & $\mathrm{Ti}$ & $\mathrm{Al}$ \\
\hline AA1100 & 0.01 & - & - & 0.6 & 0.2 & - & - & 0.02 & Balance \\
AA7075 & 5.5 & 2.4 & 1.7 & 1.4 & 0.2 & 0.05 & 0.07 & - & Balance \\
\hline
\end{tabular}

strength, ductility, strength, and thermal stability. The interface shear actions, strengthening mechanisms, and deformation behaviors for the LMCs consisting of UFG metals and alloys have not been studied in depth. The LMCs with ultrafine grains and nanostructured precipitates have been designed and fabricated using coarse grained materials with the "top-down" technique of ARB. The aim of this project was to investigate the interface shear actions and strengthening mechanisms of nanostructured Al alloy LMCs.

\section{Experimental Materials and Procedures}

2.1. Materials. In this study, the LMC is composed of the commercial pure aluminum (AA1100) and the high strength aluminum alloy (AA7075), and the detailed chemical compositions are shown in Table 1.

2.2. Experimental Procedures. The roll bonding experiments were carried out in an LG-300 rolling mill. The diameters of rollers were $170 \mathrm{~mm}$, the maximum rolling force was about $300 \mathrm{kN}$, and the rolling speed was about $0.2 \mathrm{~m} / \mathrm{s}$. The fabrication process of UFG LMCs consisting of AA1100 and AA7075 can be divided into three main stages: (I) hot roll bonding (HRB), (II) hot ARB, and (III) hot and cold rolling. The schematic diagram for fabricating nanostructured Al alloys LMCs is shown in Figure 1. The roll bonding process of LMCs with different numbers of layers is shown in Figure 2.

(I) Hot Roll Bonding (HRB) Process. The $2 \mathrm{~mm}$ thick AA1100 (denoted as A) and $3 \mathrm{~mm}$ thick AA7075 (denoted as B) were both cut to a size of $300 \mathrm{~mm} \times 150 \mathrm{~mm}$. The surfaces of the sheets were polished using a stainless steel wire brush with a $0.2 \mathrm{~mm}$ diameter. These metal sheets were stacked in the order of "ABABA," and then the four corners of the stacks were riveted together. The total thickness of the prerolled stacked sheets was about $12 \mathrm{~mm}$. The stacked sheets were heated to $460^{\circ} \mathrm{C}$ and held at this temperature for about 


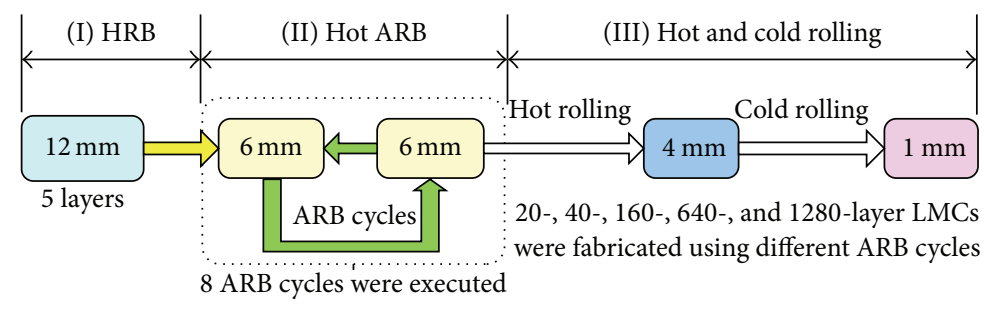

FIGURE 2: Roll bonding process of LMCs with different layers.

30 min, and then the stacked sheets were rolled from a thickness of $12 \mathrm{~mm}$ to $6 \mathrm{~mm}$. The reduction in thickness by rolling is about 50\%. The $6 \mathrm{~mm}$ thick, 5-layer AA1100/AA7075 LMC sheets could be successfully fabricated after the first stage HRB process.

(II) Hot ARB Process. The 5-layer AA1100/AA7075 LMC sheet, obtained from the HRB stage, was cut into four pieces of LMC with a thickness of $6 \mathrm{~mm}$, and then two pieces were stacked together, and the four corners were riveted together. The total thickness of the prerolled slab was about $12 \mathrm{~mm}$. The prerolled slab was heated to $460^{\circ} \mathrm{C}$, and the temperature was held for about 30 minutes. The stacked LMC sheet was rolled from $12 \mathrm{~mm}$ into $6 \mathrm{~mm}$. These processes are called the 1st ARB cycle. The $6 \mathrm{~mm}$ thick, 10-layer LMC sheet can be successfully fabricated after the 1st ARB cycle. The different layers of the LMC sheet can be fabricated by repeating the ARB process. The $6 \mathrm{~mm}$ thick, 20-layer LMC sheet was fabricated after the 2nd ARB cycle. In the same way, the 3rd ARB, 5th ARB, 7th $\mathrm{ARB}$, and 8th ARB can be similarly carried out, and the 40layer, 160-layer, 640-layer, and 1280-layer LMC sheets were obtained, respectively.

(III) Hot and Cold Rolling Process. During each of the ARB cycles, the $6 \mathrm{~mm}$ thick AA1100/AA7075 LMC sheets obtained were rolled into $4 \mathrm{~mm}$ thick sheets at $460^{\circ} \mathrm{C}$. Then, the $4 \mathrm{~mm}$ thick LMC sheets were rolled into $1 \mathrm{~mm}$ with a reduction of $10 \%$ with each rolling pass at room temperature. The diameters of the rollers of the cold rolling mill were $170 \mathrm{~mm}$. The $1 \mathrm{~mm}$ thick LMC sheets with different layers could be obtained when performing the cold rolling process for the LMCs.

2.3. Microstructure Analysis and Mechanical Testing. The meso- and microstructure of the processed LMCs was investigated using scanning electron microscopy (SEM, TESCAN VEGA II LMU) and transmission electron microscopy (TEM, Zeiss Libra 200FE). Tensile tests were carried out using three tensile samples for each LMCs sheet at room temperature on a Shimadzu AG-X testing machine operated at a constant crosshead speed with an initial strain rate of $5.5 \times$ $10^{-4} \mathrm{~s}^{-1}$. The dimensions of the tensile test sample are shown in Figure 3. To investigate the tensile fracture behavior, the fracture surface of the tensile samples was characterized by SEM for the LMCs with different numbers of layers.

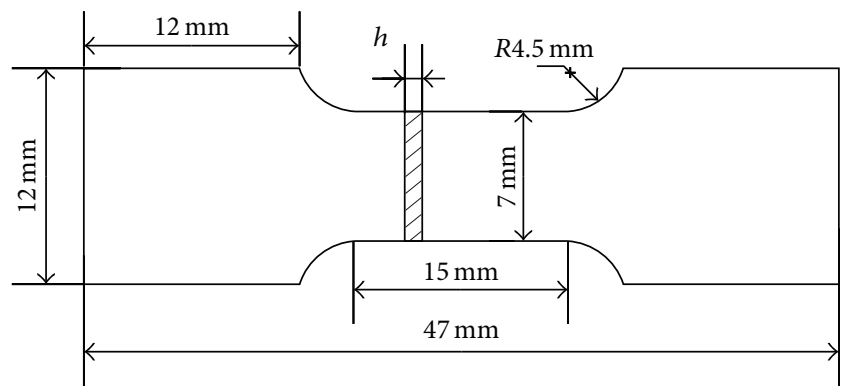

Figure 3: Dimensions of tensile test sample.

\section{Results and Discussion}

3.1. Microscopic Analysis. Figure 4 shows the mesostructure images in the rolling direction- (RD-) normal direction (ND) sections of the $75 \%$ cold rolled LMCs with different numbers of layers obtained using SEM.

Figure 4 shows that the LMCs have achieved good bonding with hot ARB; that is, in the bonding interface no cracking and delamination defects were observed. The inhomogeneous deformations have occurred in each of the constituent metals based on the observation of bonding interface topographies. For the 5-layer LMC (as shown in Figure 4(a)), the layer thickness is basically uniform, and the bonding interfaces are almost straight. The fluctuation of layer thickness starts with 20-layer LMCs (Figure 4(b)), and the degree of fluctuation is enhanced with increasing numbers of layers below a certain layer number. The fluctuation of the bonding interfaces is often manifested as the necking of AA7075 layers and waviness of AA1100 layers. These features appear to be evident in Figure 4(c).

During the initial cycles of ARB, the soft layers thin down faster than the hard layers. With the increase of strain, constituent metals begin to incur the nonuniform deformations, and the thickness of layers starts to vary. Necking starts to occur in the hard layer, and the soft layer protrudes into the hard layer filling it up $[23,42,48,49]$. The necking of the AA7075 layers causes its upper and lower surfaces to form an angle of about $30^{\circ}$, and the waviness of the AA1100 layers results in an angle between the bonding interfaces and the rolling direction of $\pm 15^{\circ}$ (Figure 4(b)). With the increase of the ARB cycles, the hard layers thin down and even fracture in some places. This is because the different flow behaviors 


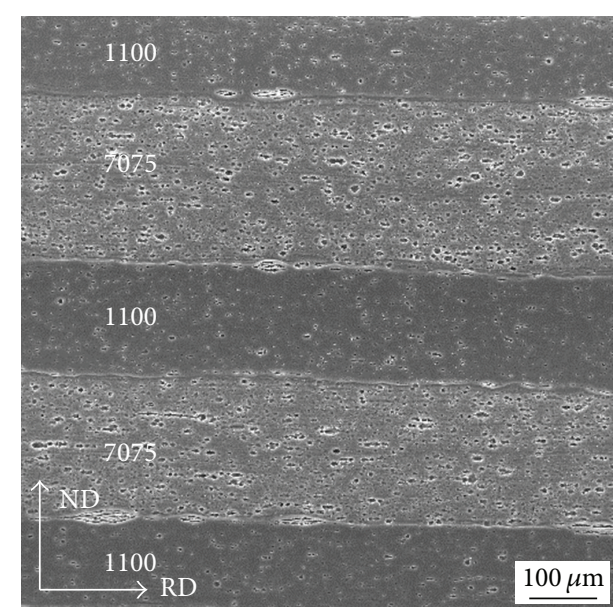

(a)

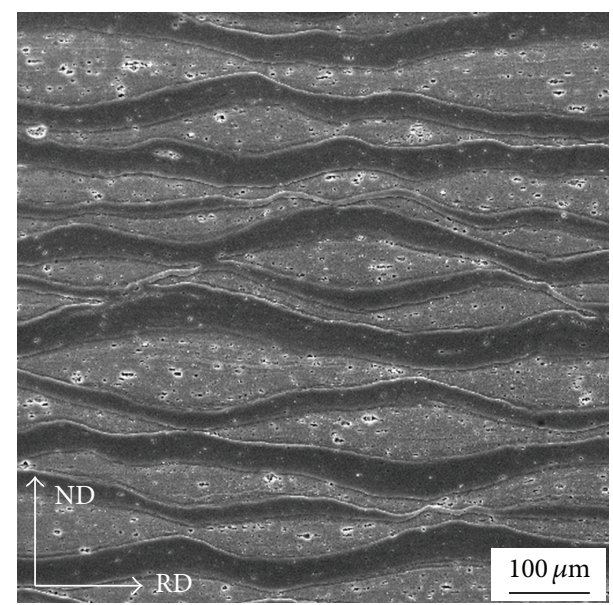

(c)

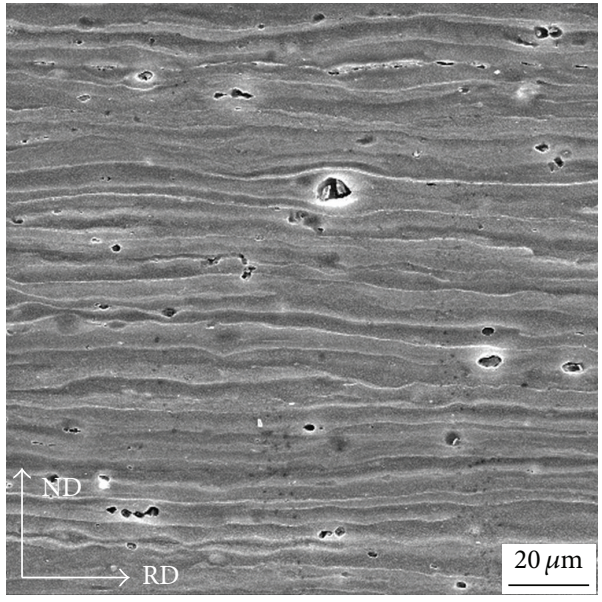

(e)

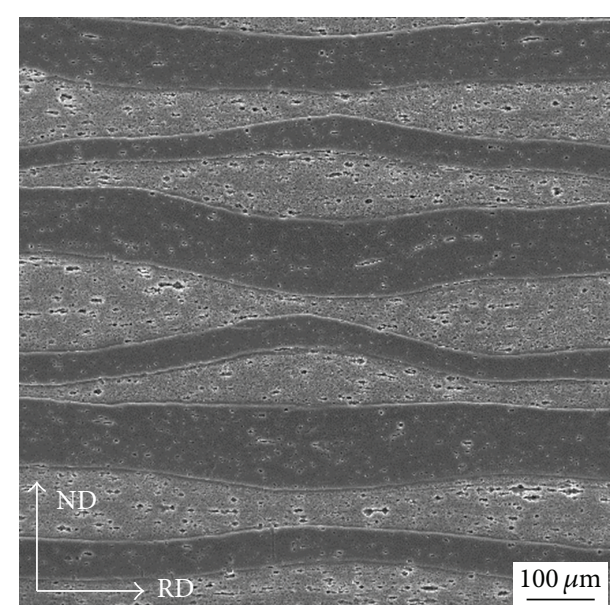

(b)

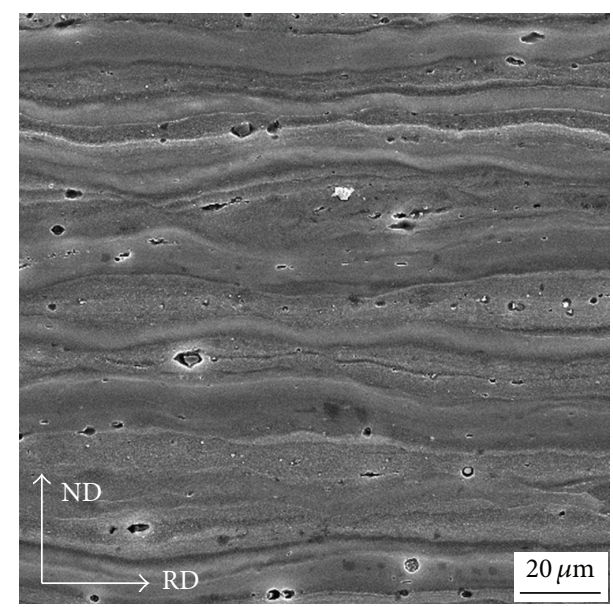

(d)

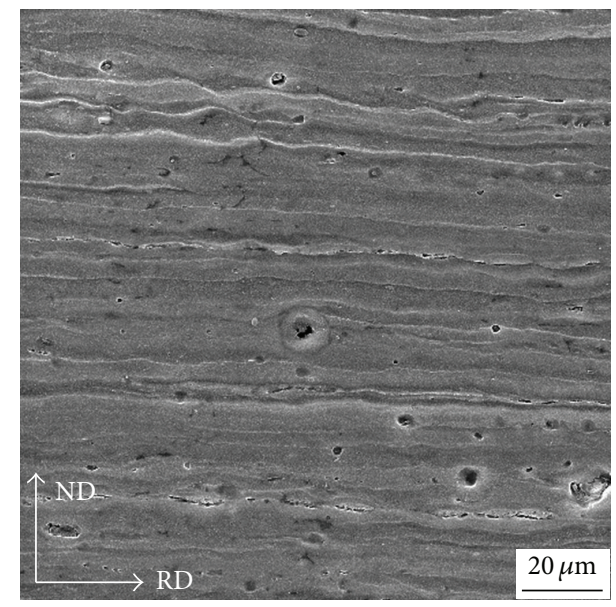

(f)

FIGURE 4: SEM macroscopic morphologies in RD-ND sections of the cold rolled LMCs. (a) 5 layers; (b) 20 layers; (c) 40 layers; (d) 160 layers; (e) 640 layers; (f) 1280 layers. 

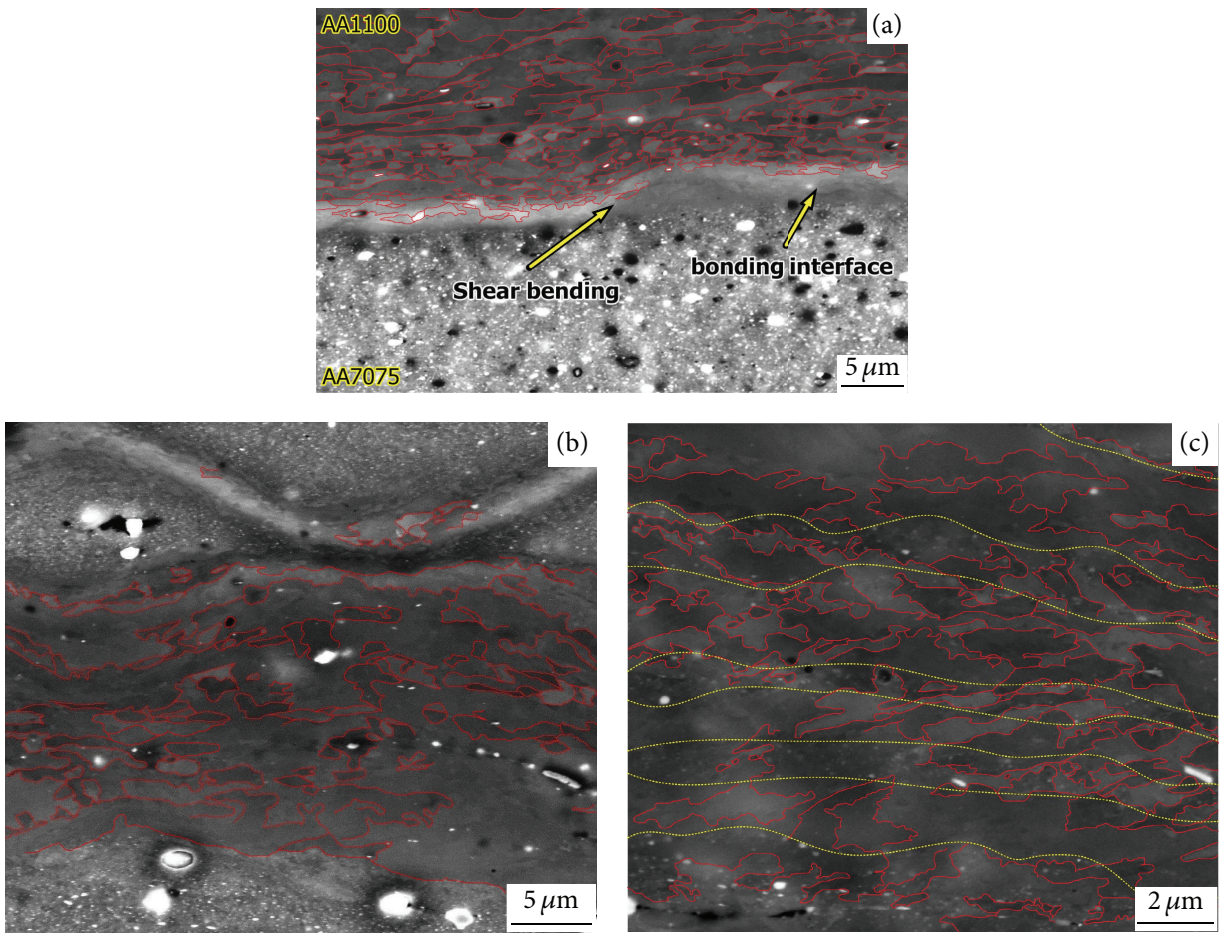

FIGURE 5: Microstructure of bonding interface of LMCs with different layers. (a) 20 layers; (b) 80 layers; (c) 1280 layers.

between the dissimilar metal layers (AA7075 and AA1100) induce an in-plane shear stress at the interface of adjacent layers, thereby resulting in a shear instability of the AA7075 layers when the in-plane shear stress becomes considerably greater than the yield strength (in pure shear conditions) of AA7075. This is largely consistent with previous studies [22] which reported a $\pm\left(17^{\circ} \pm 3^{\circ}\right)$ deviation angle between the bonding interface and the rolling direction of the $\mathrm{Al} / \mathrm{Al}(\mathrm{Sc})$ multilayered sheets. Previous studies show that the strength of dissimilar LMCs fabricated by ARB first decreases and then increases; the elongation decreases after two rolling cycles [37-42]. The increase of strength is contributed by the hardening of sample caused by piling up of the dislocations and grain refinement $[20,23,48,49]$.

When the number of layers is larger than 160 , the average thickness of the layers is about several micrometers. The nonuniform deformation was caused by fluctuation and curvature of bonding interfaces which weakened with an increase of layer numbers because of the constraints of layer sizes. Slight thickness fluctuation and curvature of the AA1100 layers and necking of the AA7075 layers can be observed. The necking of the AA7075 layers appears as the short-range characteristic (Figures $4(\mathrm{~d})-4(\mathrm{f})$ ). Basically a uniform distribution of the AA1100 and AA7075 layers is obtained for the 1280-layer LMCs (Figure 4(f)).

Figure 5 shows the microstructures of bonding interfaces in the RD-ND sections of the $75 \%$ cold rolled LMCs with different numbers of layers.

From Figure 5(a), it can be seen that the microstructure of the AA1100 layer of the 20-layer LMC has an obvious gradient. Ultrafine equiaxial and elongated grains and subgrains can be observed near the bonding interface, with an average size of about $800 \mathrm{~nm}$. With increasing distance from the bonding interface, the microstructure gradually transfers into predominantly elongated grains with an average grain size of about $1.5 \mu \mathrm{m}$. Grains or subgrains far away from the interface are coarser than those near the interface, and their average grain size is about $\sim 6 \mu \mathrm{m}$. With increasing number of layers, the thickness of each layer gradually becomes smaller. Thus, the distribution of shear strains between the layers gets more uniform in direction of the thickness, making the microstructure of each layer finer. The average equivalent size of the 80-layer LMCs is about $\sim 6 \mu \mathrm{m}$, as shown in Figure 5(b). Ultrafine grains and subgrains were obtained for the 1280 layer LMCs with a lamellar spacing of about $300 \mathrm{~nm}$.

The grain refinement is mainly attributed to the shear action of dissimilar metals at the bonding interface [49]. The initial strengths as well as strain hardening behaviors of the two constituent metals (AA1100 and AA7075) are different. The dissimilar constituent metals generate obviously dragging actions during the cold rolling process because of the differences of deformation resistances and strain hardening behaviors. In the AA7075 layers necking occurs easily because of the poor ductility during the thickness reduction by rolling. The necking of the AA7075 layer and the shear actions at the bonding interface of dissimilar metals are shown in Figure 6. The shear stress results in the strong refinement of grains at the bonding interface of dissimilar metals. This is the reason that grains far away from the interfaces are coarser than those close to the bonding interfaces. 


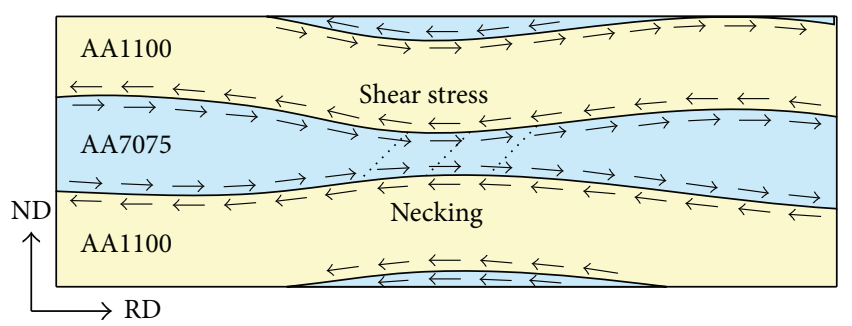

FIGURE 6: Necking of the AA7075 layer and shear actions at the bonding interface.

The formation of necking is closely related to the shear bands generated during the rolling process. The shear bands are the result of nonuniform deformation of the constituent metals of LMCs [44]. Figure 5(a) shows the shear band and bonding interface of 20-layer LMCs. There is shear bending along the propagated direction of the shear band at the bonding interface. This is a sign of necking occurring in the AA7075 layers.

The microstructures of AA1100 and AA7075 layers for the 1280-layer LMCs were characterized by TEM, as shown in Figure 7.

From Figure 7(a), it can be seen that the average grain size is about $640 \mathrm{~nm}$. The microstructure of the AA1100 layers in the 1280-layer LMCs mainly contains equiaxed grains surrounded by clear grain boundaries, which contain a lower dislocation density. From Figure 7(b), it can be seen that a large amount of nanosized spherical shaped precipitates can be observed in the AA7075 layers. The AA7075 layers of the 1280-layer LMCs obviously experience dynamic recovery leading to rearrangement of dislocations and resulting in a lower dislocation density. From Figure 7, it can be seen that the LMCs are composed of AA1100 layers with the UFG and AA7075 layers with the nanostructured precipitates ( $\eta$ phase, $\mathrm{MgZn}_{2}$ ).

3.2. Mechanical Properties of LMCs. Figure 8 shows the mechanical properties of cold rolled LMCs with different numbers of layers.

From Figure 8, the tensile tests of 20- and 40-layer LMCs show poor ductility, almost no plastic elongation, and fracture occurs quickly beyond the yield point. The other layered LMCs have shown the different levels of yielding plateau after the tensile yielding. The as-rolled LMCs have hardly any strain hardening capability. This is consistent with tensile curves of reported LMCs composed of dissimilar metals, such as AA6014/AA5754 and AA1050/AA5754 [37, 50].

Figure 9 shows the relationship between yield strength and elongation to fracture of LMCs with the number of layers based on the tensile curves of Figure 8. It can be seen that the strength shows a stepwise increase. The yield strength is about $280 \mathrm{MPa}$ for layer numbers below 40 . The strengths increase to $\sim 340 \mathrm{MPa}$ for up to 160 layers. The strength of 640-layer LMCs increases to a maximum of $371 \mathrm{MPa}$. Then, the strength slightly decreases to $365 \mathrm{MPa}$ for the 1280-layer LMCs.
Figure 9 shows that the elongation to fracture of LMCs reaches a minimum at 40 layers. It decreases from 3.5\% for 5 layers to $0.9 \%$ for 40 layers and then increases again to the maximum of $4.6 \%$ for 1280 layers. It is worth noting that the extremely low elongations (less than about $1 \%$ ) of the 20 and 40-layer LMCs exactly coincide with the severe interface curvature and necking of the constituent metals, as shown in Figures 4(b) and 4(c). Furthermore, the local necking easily leads to the thinning of the AA7075 layers and generates local stress concentrations under an external load. The stress concentrations lead to local yielding and straining of metals, significantly decreasing the strength of LMCs if the local deformation continuously propagates. The instable interface curvature and individual layer shape lead to instabilities of the mechanical properties of LMCs. Previous studies show that the local accumulation of nonuniform strain causes the instability of mechanical properties, which can be proved by the results reported in the literatures $[14,36,42,48,49]$. The waviness of the bonding interfaces changes the total thickness of AA7075 layers along different sections of the LMCs sheets. Therefore, the yield strength and elongation to fracture of LMCs decrease with increasing variation of individual layer shape and necking $[14,49,51]$. With increasing number of layers, the average layer thickness gradually reduces, the curvature of the bonding interfaces weakens, and the necking of AA7075 layers shows local short-range characteristic. As a whole, the AA1100 and AA7075 layers approximately become uniform and continuous along the sheet cross section, as shown in Figures 4(d)-4(f). Therefore, the elongation to fracture of LMCs gradually increases for more than 160 layers, as shown in Figure 9.

3.3. Necking and Waviness of Dissimilar Metals. The necking of a hard layer is a characteristic of the dissimilar LMCs fabricated by roll bonding. The formation of necking is largely attributed to the difference of properties and thickness ratio of dissimilar metals. The great differences of mechanical properties (e.g., flow stress, yield strength, hardness, and strain hardening exponent) result in the uncoordinated deformation of each layer during roll bonding. In order to obtain coordinating deformation of dissimilar metals, the flow stress ratio of the two metals (hard layer and soft layer) needs to be less than $2-2.5[52,53]$. The initial thickness ratio has an important influence on the deformation of the constituent metals. A larger thickness ratio between hard layers and soft layers, larger critical deformation for necking, and the necking tend to be smaller. That is to say, the thickness ratio of the constituent metals of the LMCs impacts the continuity and uniformity of deformation [54].

Figure 4(b) shows that obvious necking had occurred at the AA7075 layers. The hardness of the constituent layers was tested using the different reductions during the cold rolling process. In view of the effect of thickness of layer on the indentation size, the testing load for AA1100 layers was $50 \mathrm{~g}$ for $10 \mathrm{~s}$ and for the AA7075 layers was $100 \mathrm{~g}$ for $10 \mathrm{~s}$. The results of the microhardness tests are shown in Figure 10.

From Figure 10(a), it can be seen that the hardness value added $(13 \mathrm{HV})$ to the AA1100 layers for the first three passes 


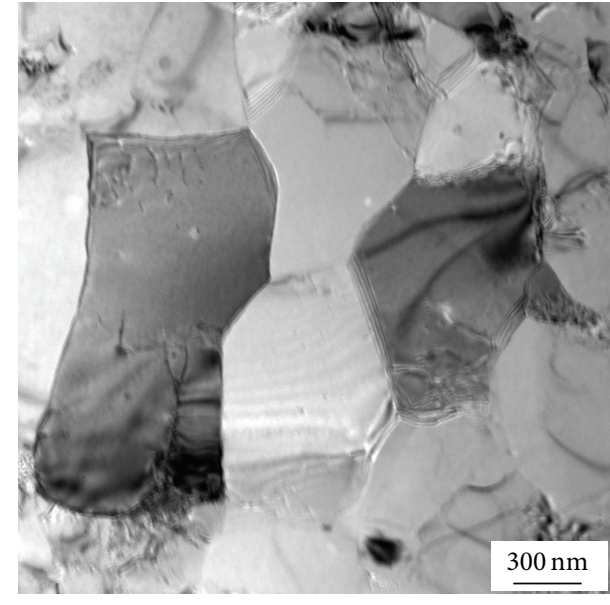

(a)

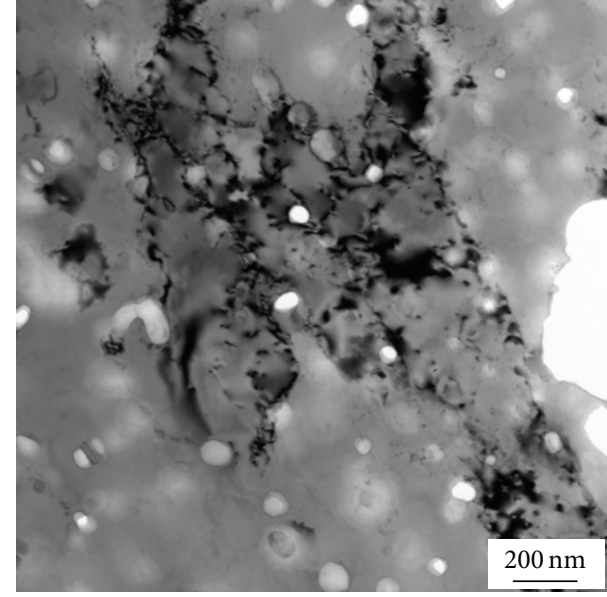

(b)

FIGURE 7: TEM micrographs of cold rolled LMCs observed from RD-transverse direction (TD). (a) AA1100 layer; (b) AA7075 layer.

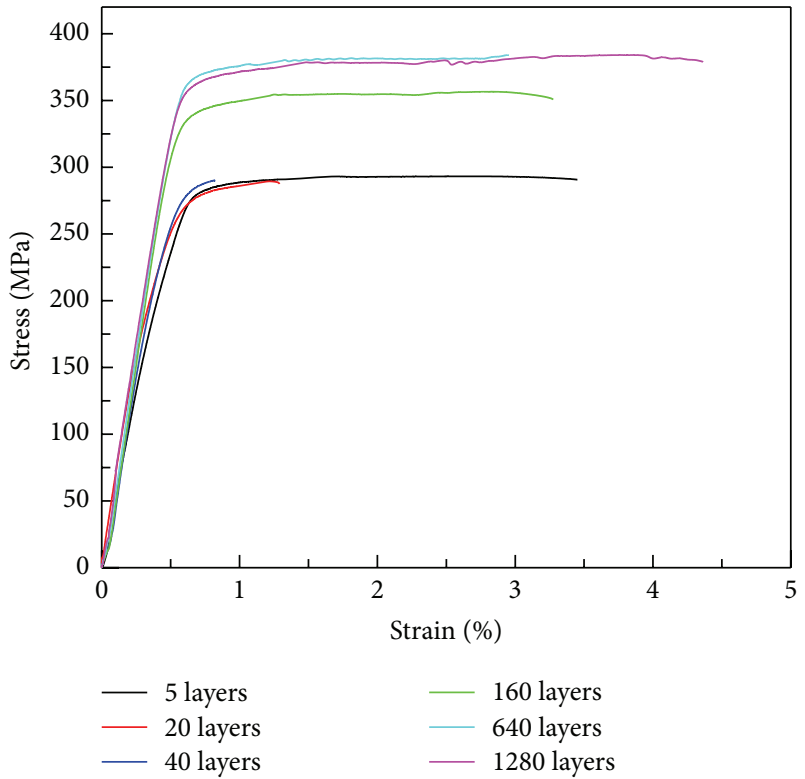

FIGURE 8: Tensile stress-strain curves for as-rolled LMCs with different numbers of layers.

(total reduction 25\%) is larger than the hardness value added (8 HV) to the AA7075 layers. Nevertheless, the hardness values added to the AA7075 layers are larger than those added to AA1100 layers in the subsequent rolling passes (larger than 25\%). This is because the plastic deformation is mainly concentrated on the AA1100 layers. The extent of strain hardening of the AA1100 layers is larger than that of the AA7075 layers. With the increase of cold rolling passes, the deformation of the AA1100 layers will partly be distributed to the AA7075 layers, and it will result in the increase of hardness of the AA7075 layers. In addition, the solid solution atoms and the second phase particles of the AA7075 layers could hinder the movement of dislocations, thus enhancing the multiplication of the dislocations. All of these reasons

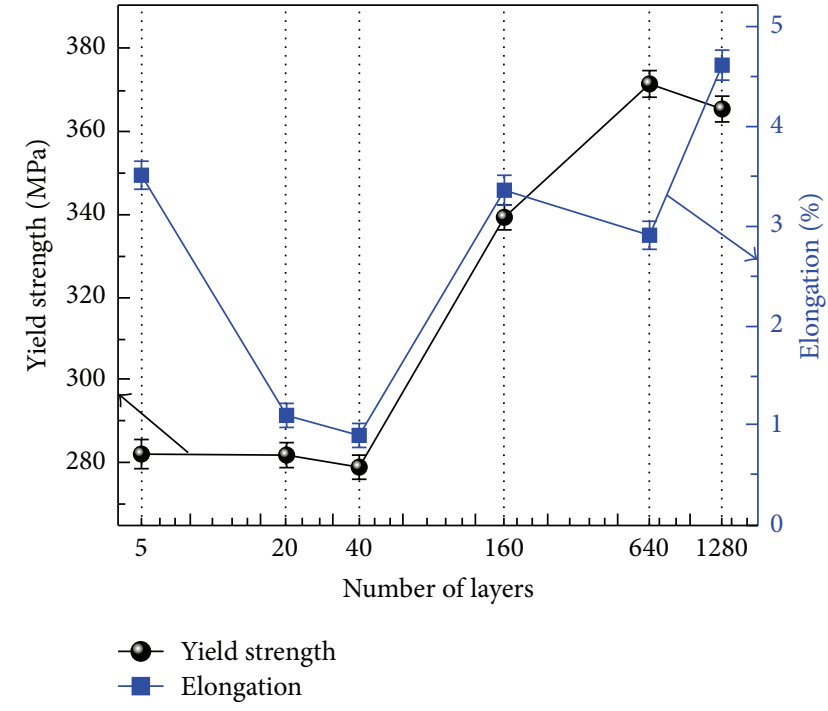

FIGURE 9: Yield strength and elongation to fracture versus the numbers of layers for as-rolled LMCs.

lead to the increase of strain hardening rate of the AA7075 layers and result in the hardness values added to the AA7075 layers being larger than those added to the AA1100 layers. An obvious phenomenon is that the hardness of AA1100 layers is much less than that of the AA7075 layers. This leads to the extension of AA1100 layers making them larger than the AA7075 layers during the rolling process. Therefore, the AA1100 layers were compelled to incur waviness to accommodate the redundant extension.

Figure 10(b) shows the variation of hardness ratio of AA7075 and AA1100 layers with the different reductions in thickness. Before pre-cold rolling, the hardness of the AA1100 layers is a low hardness value $(26 \mathrm{HV})$ which is because of the annealing treatment; the hardness of AA7075 layers is high $(111 \mathrm{HV})$ because of the solid solution and precipitation 


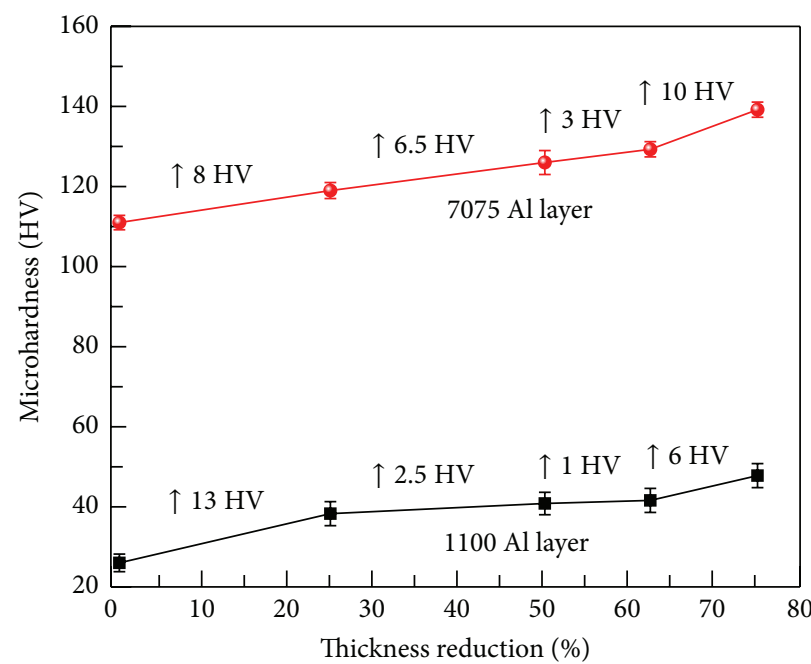

(a)

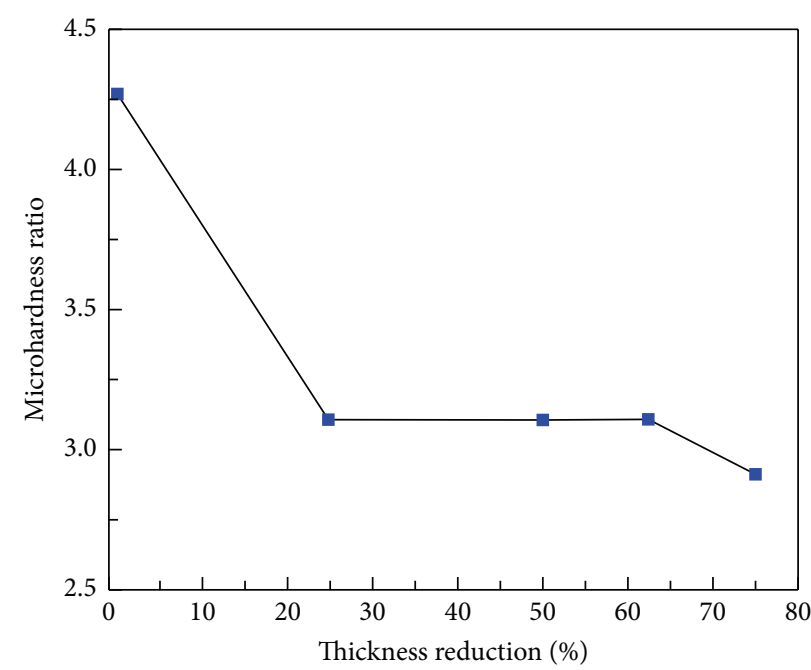

(b)

FIGURE 10: Microhardness (a) and microhardness ratio (b) of AA7075 and AA1100 layers versus total thickness reduction in the 20-layer LMCs during cold rolling.

strengthening effects. Therefore, the hardness ratio of the constituent metals was 4.3 , which is much higher than that required for coordinating deformation of dissimilar metals. The hardness ratio of the constituent metals decreases to 3.0 with the increase of strain hardening in the subsequent rolling passes. However, the hardness ratio of the constituent metals is still high enough so that it can easily lead to necking of AA7075 layers and waviness of AA1100 layers during the roll bonding process.

3.4. Shear Actions of Dissimilar Metals. The differences of the mechanical properties of the constituent metals lead to the shear actions and "drag" with each other at the bonding interface. The shear stress is indicated by $\tau$ [22].

In the rolling plane, the AA7075 layers of the LMCs yield under the common actions of compressive and shear stresses. This must satisfy the von Mises yield criterion:

$$
\sigma+\tau=\sigma_{7075}
$$

where $\sigma_{7075}$ is the flow stress of the AA7075 layers and $\sigma$ is the flow stress of LMCs, and it can be evaluated using the rule of mixtures [7]:

$$
\sigma=\varphi_{1100} \sigma_{1100}+\varphi_{7075} \sigma_{7075}
$$

where $\sigma_{1100}$ is the flow stress of the AA1100 layers and $\varphi_{1100}$ and $\varphi_{7075}$ are the volume fraction of the AA1100 and AA7075 in LMCs, respectively. Here, $\varphi_{1100}=\varphi_{7075}=50 \%$, and formula (2) can be written as

$$
\sigma=0.5 \sigma_{1100}+0.5 \sigma_{7075}
$$

Based on formulas (1) and (3), the following formula can be obtained:

$$
\tau=\frac{1}{2}\left(\sigma_{7075}-\sigma_{1100}\right)
$$

TABLE 2: Flow stresses of AA1100 and AA7075 layers and shear stresses at different thickness reductions.

\begin{tabular}{lccccc}
\hline \multirow{2}{*}{ Stress (MPa) } & \multicolumn{5}{c}{ Reductions (\%) } \\
& 0 & 25 & 50 & 62.5 & 75 \\
\hline$\sigma_{1100}$ & 84 & 125 & 133 & 136 & 156 \\
$\sigma_{7075}$ & 364 & 391 & 412 & 423 & 455 \\
$\tau$ & 140 & 133 & 139.5 & 143.5 & 149.5 \\
\hline
\end{tabular}

According to the relationship of flow stress $\sigma_{\text {flow }}$ and hardness $H$ [55],

$$
\sigma_{\text {flow }}=9.807 \times 0.1^{n-2} \times \frac{H}{3},
$$

where the strain strengthening of the metals' $n$ value is about 2. Substituting the hardness data of Figure 10(a) into formula (5), the flow stresses $\sigma_{1100}$ and $\sigma_{7075}$ under different rolling reductions can be obtained, and then substituting the flow stresses $\sigma_{1100}$ and $\sigma_{7075}$ into formula (4) can be used to calculate the shear stress $\tau$ at the bonding interface. The results are shown in Table 2.

The formation condition of shear bands caused by the shear stress is

$$
\tau \geq \frac{\sigma_{y-\mathrm{Al}}}{\sqrt{3}}
$$

where $\sigma_{y \text {-Al }}$ is the yield stress of metals in uniaxial tension and $\sigma_{y \text {-Al }} / \sqrt{3}$ is the yield stress of metals in pure shear.

Figure 11 shows the tensile curves of AA1100 cold rolled by $75 \%$ and AA7075 cold rolled by $67 \%$. It can be seen that the yield stresses of AA1100 and AA7075 are $157 \mathrm{MPa}$ and $330 \mathrm{MPa}$, respectively. In view of the effect of strain strengthening of the constituent metals, the yield stresses obtained from Figure 11 can be considered as the maximum values of the AA1100 and AA7075 layers. Substituting the 


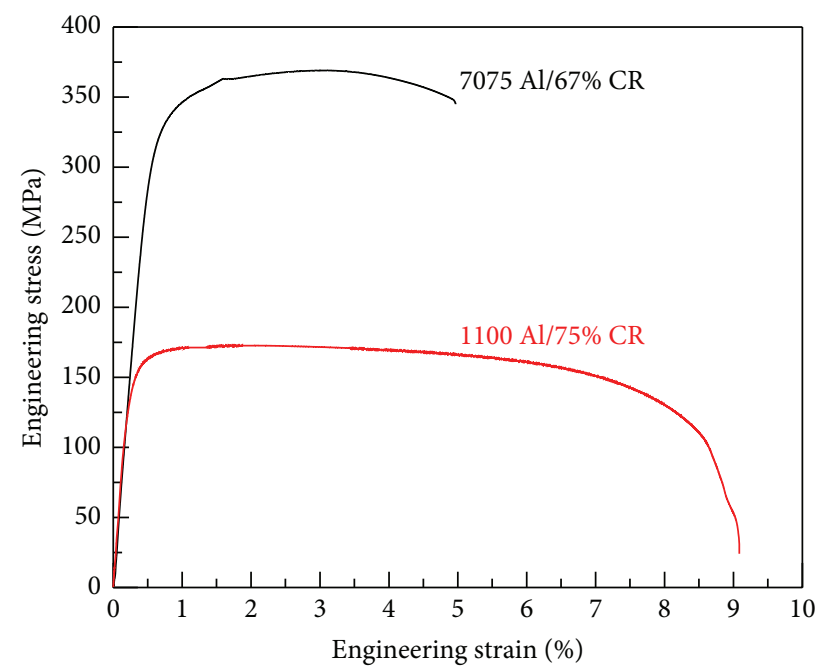

FIgURE 11: Tensile curves of AA1100 and AA7075 after 75\% and 67\% cold rolling (CR).

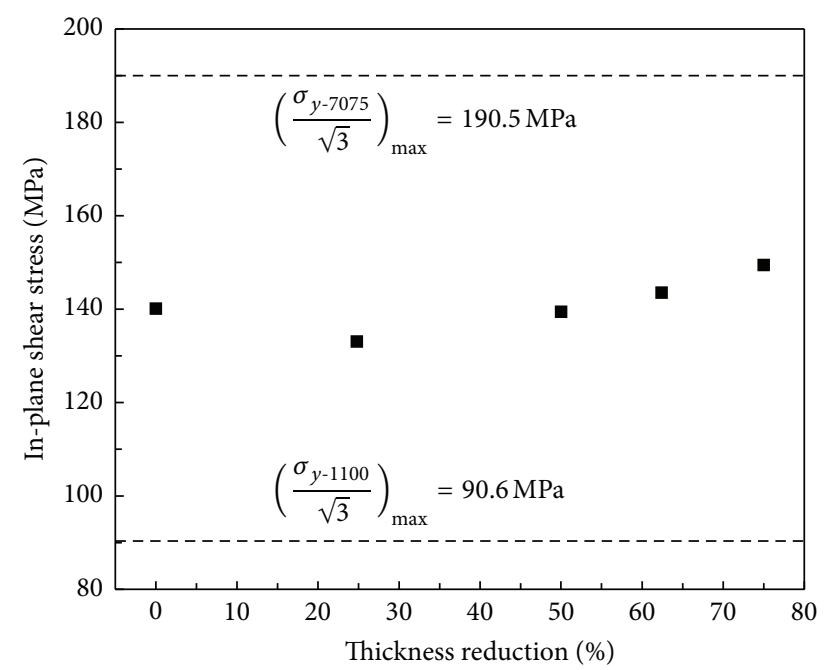

FIGURE 12: Magnitude of in-plane shear stress versus total thickness reductions for a 20 -layer sample during cold rolling process. The two dashed lines denote the yield strength in the pure shear condition for $75 \%$ cold rolled AA1100 and $67 \%$ cold rolled AA7075, respectively.

stress values into formula (6), the interface shear stress can be calculated, as shown in Figure 12. During the cold rolling process, the shear stress at the interface of dissimilar metals is much larger than the pure shear stress of the AA1100 layers. But, it is likely to be less than the pure shear stress of the AA7075 layers. This indicates that the shear stress easily leads to shear bands in the AA1100 layers but is hard to achieve the shear bands in AA7075 layers. This speculation is consistent with the experimental results shown in Figure 5.

The necking of the AA7075 layers is not caused by shear strain until an additional external stress is imposed. The additional stress can be indicated as

$$
\Delta \sigma=\frac{\sigma_{y-7075}}{\sqrt{3}}-\tau .
$$

Furthermore, the shear strain bands of the AA1100 layers will expand to the bonding interface, and then the movements of shear bands are blocked by the bonding interface of dissimilar metals. The blocked shear strain leads to stress concentration, penetrates the bonding interface into the AA7075 layers when the concentrated stress reaches the required additional stress, and then causes the necking of the AA7075 layers.

The studies of ARB for dissimilar metals show that the thickness of the layer gradually reduces with the increase of the ARB cycles, which leads to the fractured fragments of hard metals that are uniformly distributed in the soft substrate metal $[30,39]$. However, some slight waviness was observed in the 160-layer, 640-layer, and 1280-layer LMCs, although most of the regions along the cross section have good continuity. The reasons for this can be attributed to three aspects as follows. At first, with the increase of the layers, the grains of the AA1100 layers were rapidly refined and the dislocation density of the AA1100 layers increased significantly, and the degree of strain strengthening was enhanced, too. The hardness ratio of the AA7075 and AA1100 layers decreases to a certain extent and reduces the tendency of necking. Secondly, the influence of the interaction effects of adjacent layers to the plastic flow is more uniform when the constituent metal layers are extremely thin (less than several micrometers). Thirdly, the cold rolling reduction is about $10 \%$, which is much smaller in comparison to those for the ARB process and so it is beneficial to release the stress concentration at the bonding interface.

3.5. Strengthening Mechanism and Fracture of LMCs. For the single metals, the strengthening mechanisms of deformed AA1100 are mainly grain refinement strengthening and dislocation strengthening. The strengthening mechanisms of AA7075 are mainly attributed to the solution strengthening and precipitation strengthening. For the roll bonded LMCs consisting of AA1100 and AA7075, the strength can be evaluated using the rule of mixtures according to the strengths of each metal under approximately deformed states. According to the data shown in Figure 11, the yield stresses of the AA1100 and AA7075 are $157 \mathrm{MPa}$ and $330 \mathrm{MPa}$, respectively. The yield strength of LMCs is $244 \mathrm{MPa}$ based on the rule of mixtures. However, the strengths of the LMCs were much higher than the predicted values. The strength of the LMCs includes the other strengthening mechanisms except for grain refinement strengthening and dislocation strengthening.

Figure 13 shows the relationship of yield strength and layer thickness for $75 \%$ cold rolled LMCs.

From Figure 13, it can be seen that the yield strengths and layer thickness approximately meet the Hall-Petch relationship when the theoretical thickness of each layer is within $25 \mu \mathrm{m}$ and $1.6 \mu \mathrm{m}$; that is, the number of layers of the LMCs is 20 layers, 40 layers, 160 layers, and 640 layers. The relationship of yield strength and layer thickness can be expressed as

$$
\sigma_{s}=251+142 d^{-1 / 2},
$$




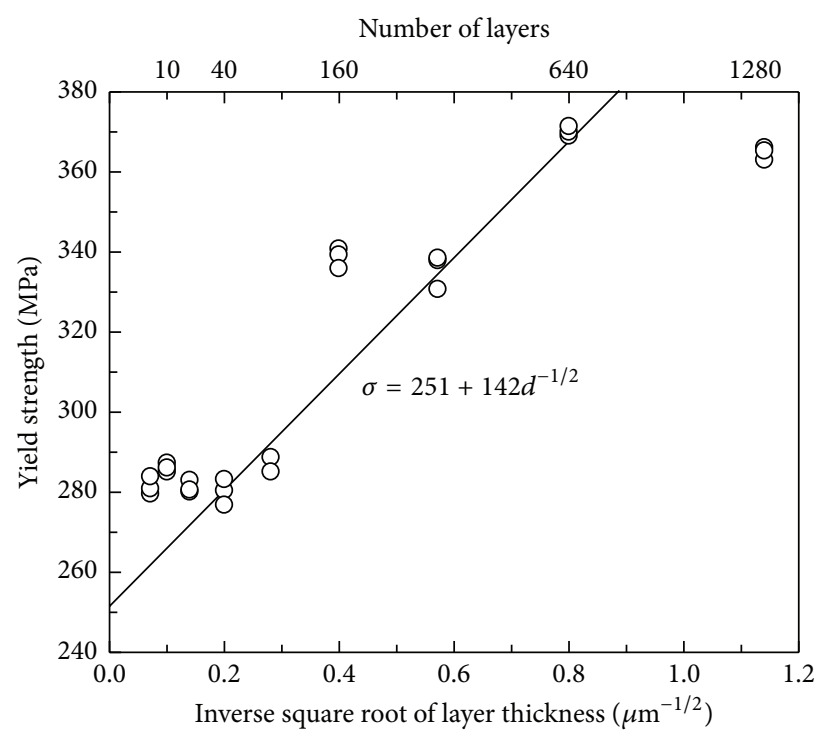

FIGURE 13: Relationship of yield strength and layer thickness for 75\% cold rolled LMCs.

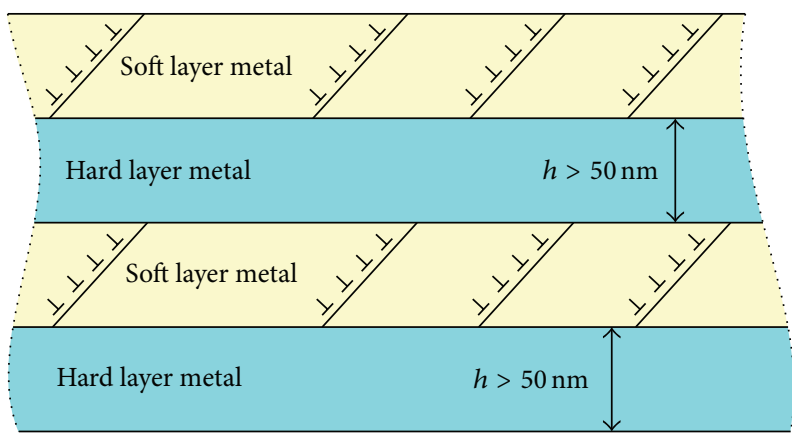

(a)

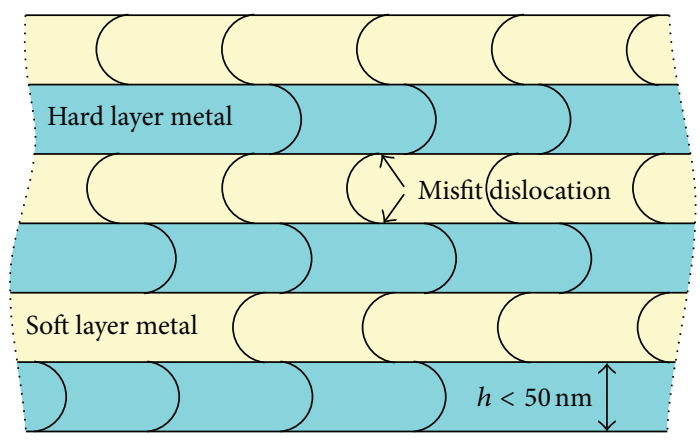

(b)

FIGURE 14: Schematic diagram of the deformation mechanism in LMCs consisting of dissimilar metals [56]: (a) as layer thickness $>50 \mathrm{~nm}$, glide dislocations move on widely spaced planes in soft layer metals and pile up at the interfaces; (b) as layer thickness $<50 \mathrm{~nm}$, dislocations move by bowing within the layers and leave misfit dislocations at the interfaces.

where $\sigma_{s}$ is the yield stress, $d$ is the thickness of metal layers, and $\sigma_{0}$ and $K$ are $251 \mathrm{MPa}$ and $142 \mathrm{MPa} \cdot \mu \mathrm{m}^{1 / 2}$, respectively. The determined strength is $244 \mathrm{MPa}$, which is very close to $\sigma_{0}$. This indicates that the determined value is reasonable, and the contributions of grain refinement and dislocation strengthening are embodied in $\sigma_{0}$.

Misra et al. [56] investigated the mechanical properties of the $\mathrm{Cu} / \mathrm{Ni}, \mathrm{Cu} / \mathrm{Nb}$, and $\mathrm{Cu} / \mathrm{Zr}$ nanolayered films using a nanoindentation technique. The research showed that the hardness and layer thickness meet the Hall-Petch relationship when the layer thickness is larger than $50 \mathrm{~nm}$. The slope $K$ is related to interface misfit of dissimilar metals. When the layer thickness is less than $50 \mathrm{~nm}$, the relationship will deviate from Hall-Petch behavior for $\mathrm{Cu} / \mathrm{X}$ nanolayered composites. At this point, the plastic flow may occur by single dislocations on closely spaced slip planes with dislocations moving by bowing within the layers, and the dislocations plate the interfaces with misfit dislocations [56]. The deformation mechanism for different layer thickness LMCs with different thicknesses of layers consisting of dissimilar metals is illustrated in Figure 14. Furthermore, Shingu et al. [57] also found that the yield strength and layer thickness have a similar phenomenon in $\mathrm{Fe}-\mathrm{Cu}$ nanosize, layered composites. The only difference is that the critical layer thickness is reduced from $50 \mathrm{~nm}$ to $35 \mathrm{~nm}$. This indicates that the effect of layer thickness on the mechanical properties is related to the dissimilar metals systems.

It is important to note that the deformation mechanism described previously is suitable for the LMCs with a uniform layer thickness. In this study, the yield strengths and layer thicknesses approximately deviate from the Hall-Petch relationship when the layer number of LMCs is more than 640 or the theoretical thickness is less than $1.6 \mu \mathrm{m}$. The average thickness of each layer of 1280-layer LMCs (with $1 \mathrm{~mm}$ thickness) is about $780 \mathrm{~nm}$. The critical layer thickness is much larger than the reported $50 \mathrm{~nm}$ of the $\mathrm{Cu} / \mathrm{X}$ nanolayered composites [58]. The reason is that there are large quantities of local necking and waviness in the LMCs because of the severe 
plastic deformation. The thicknesses of dissimilar metals were nonuniform because of the uncoordinated deformation of each layer during roll bonding. The strain strengthening showed a nonuniform distribution at the necking and waviness positions. The local accumulation of nonuniform strain caused the instability of mechanical properties $[14,36$, 37]. The stress concentration was easily generated in local necking position under external load, which leads to local yield and strain of metals and significantly decreases the strength of the LMCs. That is to say, the interface shape has an important impact on the mechanical properties and deformation mechanism of LMCs under an external load. The yield strength, tensile strength, and elongation of LMCs decreased with the increase of variation of interface shape when the number of layers was kept constant [49]. To improve the mechanical properties of LMCs, it is important to control the coordinated deformation of dissimilar metals and interface shape during the roll bonding when increasing the number of layers.

To investigate the tensile fracture behaviors, the morphology of the fracture samples was characterized using SEM for the LMCs samples with different numbers of layers, as shown in Figure 15.

As far as 5-layer LMC is concerned, as shown in Figure 15(a), the fracture surfaces of the AA1100 layers contain the ductile dimples and plastic tearing ridges near the bonding interface. This indicates that strong shear and dragging actions exist between the AA1100 and AA7075 layers. Some small voids were observed in the fracture surface of the AA7075 layers. This is because the AA7075 layers have poor ductility and fracture easily when undergoing a small deformation. In Figures 15(b)-15(c), many plastic tearing ridges can be found in the fracture surface of 20- and 40layer LMCs. This is very consistent with the low elongation to fracture and strength. In other words, the quick fracture of LMCs is caused by necking, fragmentation, and separation of the AA7075 layers. The fractures occur in such a short time that the ductile dimples do not have enough time to form and accumulate and result in tearing ridges. Figure 15(f) shows that there are many greater ductile dimples in the fracture surface of the 160-layer LMCs. This corresponds to a relatively good elongation of $\sim 3.6 \%$. For the 160 -layer LMCs with a thin layer in thickness (less than $10 \mu \mathrm{m}$ ), there is a complex stress distribution between the laminates of constituent metals because of their complex interactions during the deformation process. This leads to some special stress states at local positions, which promote the generation and propagation of ductile dimples, which are beneficial in enhancing the ductility of the LMCs.

In Figures 15(e)-15(f), the fracture surfaces of the 640and 1280-layer LMCs contain not only some ductile dimples but also interfacial delaminations. The interfacial delaminations play an important role in activating key extrinsic toughening mechanisms, particularly crack blunting, crack front convolution, and local plane stress mechanisms [59]. This is beneficial in enhancing the ductility and toughness of the LMCs. For the LMCs, some toughening mechanisms are presented, such as crack deflection, crack blunting, crack bridging, and stress redistribution. The toughness of LMCs can be improved by means of extrinsic fracture mechanisms (delaminations), if the bonding interfaces are optimized by the preparation process. The interface delaminations can essentially optimize the stress distribution of the crack tip areas and restrain crack propagation. Therefore, the interfaces of LMCs play an important role in influencing the toughness and the fracture mechanism $[58,60,61]$.

\section{Conclusions}

This paper investigated the interface shear actions and mechanical properties of nanostructured $\mathrm{Al}$ alloy laminated metal composites (LMCs). Strong interface shear actions of LMCs consisting of two dissimilar metals (AA1100 and AA7075) were attributed to the large differences in mechanical properties and flow behaviors. Through these studies, some conclusions can be drawn as follows:

(1) The LMCs consisting of AA1100 and AA7075 were fabricated using the hot ARB approach in conjunction with cold rolling, no cracks or interface delaminations were found, and good bonding is obtained. The differences of the constituent metals in mechanical properties and flow behaviors easily lead to the waviness of the bonding interfaces and nonuniform deformation. The typical characteristics are the fact that the necks occur in the hard layered metals and the bends in the soft layered metals.

(2) The cold rolling deformation of LMCs promotes shear strains of dissimilar constituent metals (AA1100 and AA7075) and accelerates refinement of grains. The blocked shear strain leads to stress concentration at the bonding interface and causes the necking of hard layered metals.

(3) The strengthening mechanisms of LMCs are mainly attributed to the grain refinement and dislocation strengthening of AA1100 layers, the solid solution and precipitation strengthening of AA7075 layers, and the laminated interfacial strengthening.

(4) The interface delaminations will be substituted for the ductile dimples as the main fracture mechanism when the number of layers of LMCs is more than 160 layers. In some situations, the ductility and toughness of LMCs can be improved by increasing the number of layers. The increase of the number of bonding interfaces will essentially optimize the stress distribution of the crack tip area and restrain crack propagation.

\section{Conflict of Interests}

The authors declare that there is no conflict of interests regarding the publication of this paper.

\section{Acknowledgments}

This research project was supported by the National High Technology Research and Development Program of China 


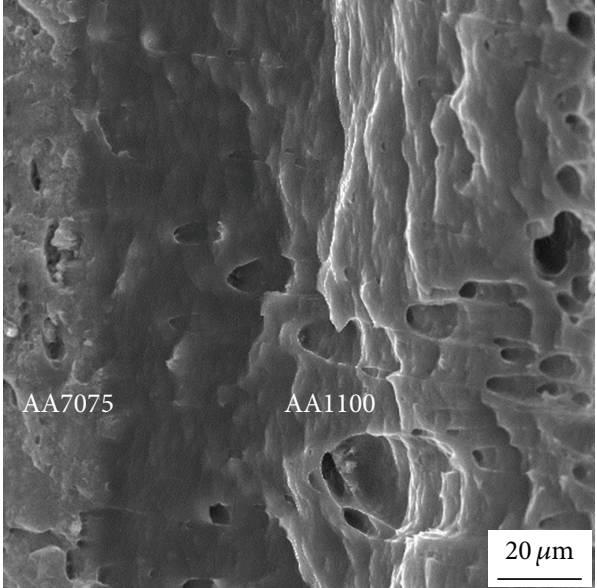

(a)

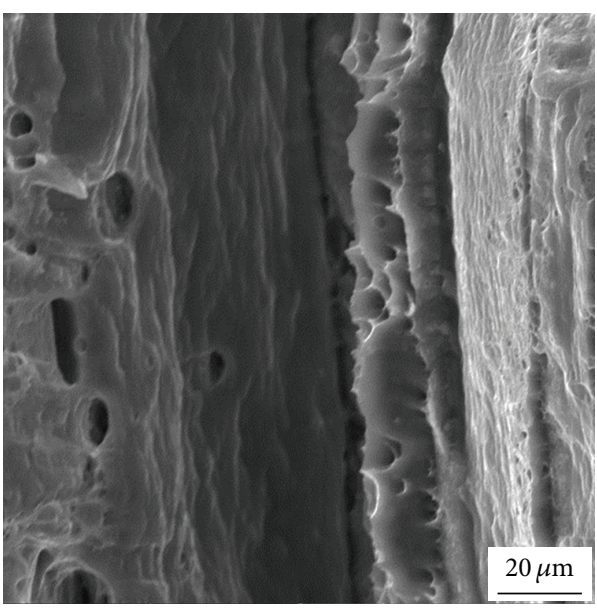

(c)

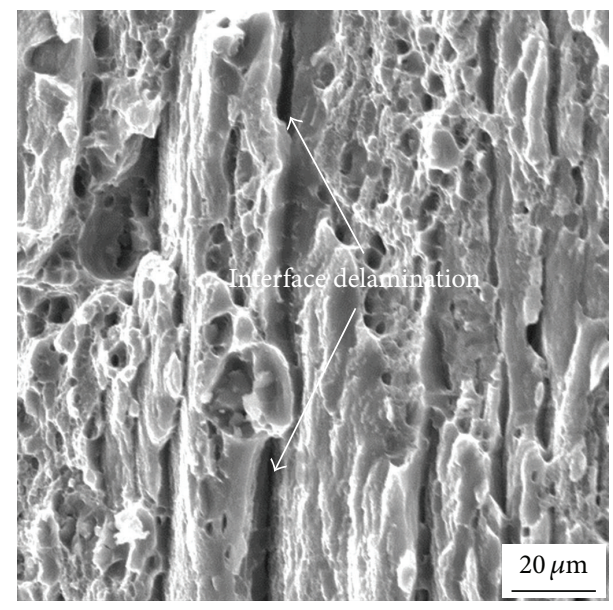

(e)

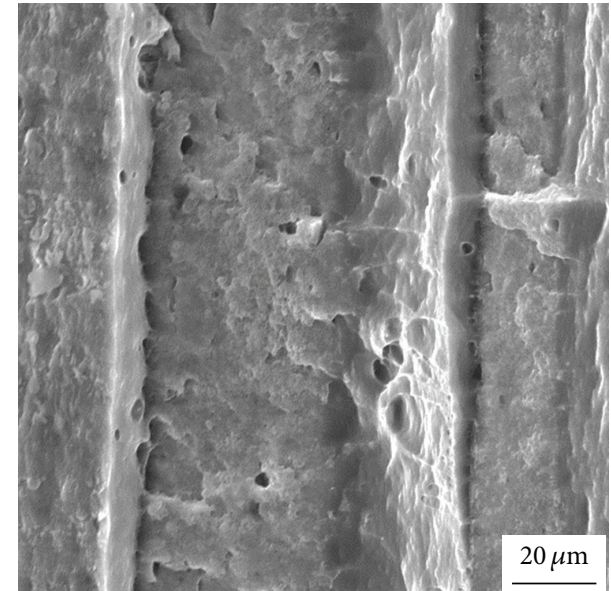

(b)

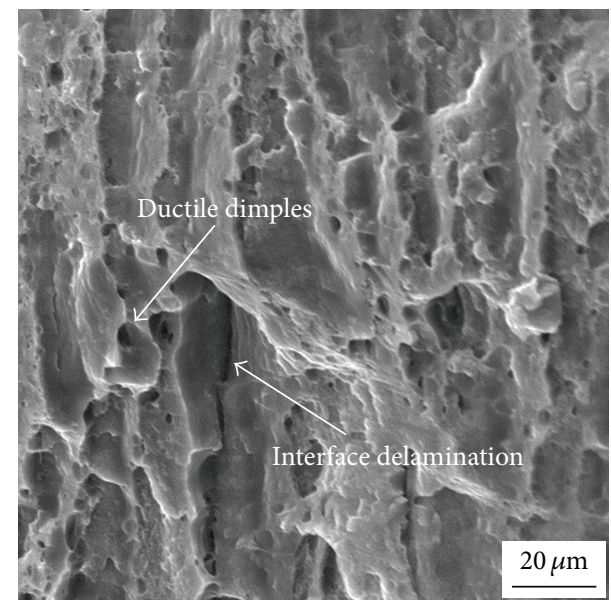

(d)

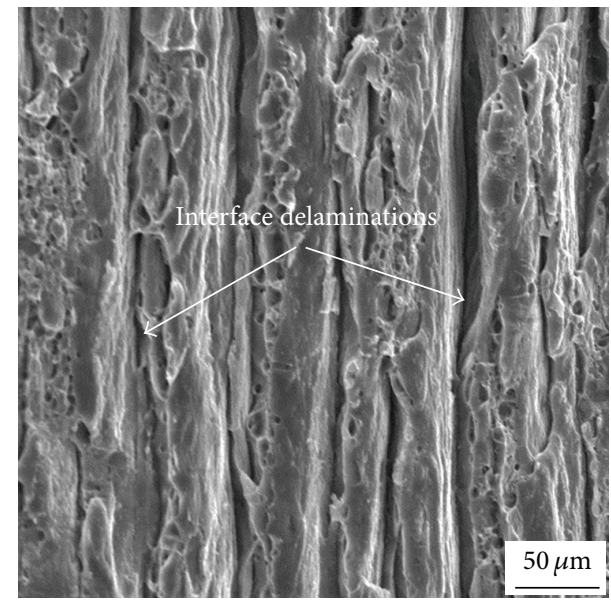

(f)

FIGURE 15: Fracture morphology of cold rolled LMCs after tensile fracture. (a) 5 layers; (b) 20 layers; (c) 40 layers; (d) 160 layers; (e) 640 layers; (f) 1280 layers. 
(863 Program, no. 2013AA031304), the Natural Science Foundation of China (no. 51204219, no. 51421001), the Fundamental Research Funds for the Central Universities (no. CDJZR14325501), the State Key Laboratory of Metastable Materials Science and Technology (no. 201512), and the Danish-Chinese Center for Nanometals.

\section{References}

[1] R. Z. Valiev, "Structure and mechanical properties of ultrafinegrained metals," Materials Science and Engineering A, vol. 234, no. 97, pp. 59-66, 1997.

[2] R. Z. Valiev, Y. Estrin, Z. Horita, T. G. Langdon, M. J. Zehetbauer, and Y. T. Zhu, "Producing bulk ultrafine-grained materials by severe plastic deformation," JOM, vol. 58, no. 4, pp. 33-39, 2006.

[3] R. Z. Valiev and T. G. Langdon, "Principles of equal-channel angular pressing as a processing tool for grain refinement," Progress in Materials Science, vol. 51, no. 7, pp. 881-981, 2006.

[4] R. Jamaati, M. R. Toroghinejad, H. Edris, and M. R. Salmani, "Fabrication of nano/ultra-fine grained IF steel via SPD processes: a review," Transactions of the Indian Institute of Metals, vol. 67 , no. 6 , pp. 787-802, 2014.

[5] L. S. Toth and C. Gu, "Ultrafine-grain metals by severe plastic deformation," Materials Characterization, vol. 92, pp. 1-14, 2014.

[6] A. M. El-Sherik and U. Erb, "Synthesis of bulk nanocrystalline nickel by pulsed electrodeposition," Journal of Materials Science, vol. 30, no. 22, pp. 5743-5749, 1995.

[7] H. Hahn, "Unique features and properties of nanostructured materials," Advanced Engineering Materials, vol. 5, no. 5, pp. 277-284, 2003.

[8] R. Z. Valiev and I. V. Alexandrov, "Nanostructured materials from severe plastic deformation," Nanostructured Materials, vol. 12, no. 1-4, pp. 35-40, 1999.

[9] R. Z. Valiev, R. K. Islamgaliev, and I. V. Alexandrov, "Bulk nanostructured materials from severe plastic deformation," Progress in Materials Science, vol. 45, no. 2, pp. 103-189, 2000.

[10] A. Azushima, R. Kopp, A. Korhonen et al., "Severe plastic deformation (SPD) processes for metals," CIRP Annals: Manufacturing Technology, vol. 57, no. 2, pp. 716-735, 2008.

[11] V. M. Segal, "Severe plastic deformation: simple shear versus pure shear," Materials Science \& Engineering A, vol. 338, no. 1-2, pp. 331-344, 2002.

[12] Y. Saito, N. Tsuji, H. Utsunomiya, T. Sakai, and R. G. Hong, "Ultra-fine grained bulk aluminum produced by accumulative roll-bonding (ARB) process," Scripta Materialia, vol. 39, no. 9, pp. 1221-1227, 1998.

[13] Y. Saito, H. Utsunomiya, N. Tsuji, and T. Sakai, "Novel ultrahigh straining process for bulk materials development of the accumulative roll-bonding (ARB) process," Acta Materialia, vol. 47 , no. 2, pp. 579-583, 1999.

[14] S. Roy, B. R. Nataraj, S. Suwas, S. Kumar, and K. Chattopadhyay, "Accumulative roll bonding of aluminum alloys 2219/5086 laminates: microstructural evolution and tensile properties," Materials and Design, vol. 36, pp. 529-539, 2012.

[15] Y. Chino, K. Sassa, and M. Mabuchi, "Enhancement of tensile ductility of magnesium alloy produced by torsion extrusion," Scripta Materialia, vol. 59, no. 4, pp. 399-402, 2008.

[16] N. Pardis, B. Talebanpour, R. Ebrahimi, and S. Zomorodian, "Cyclic expansion-extrusion (CEE): a modified counterpart of cyclic extrusion-compression (CEC)," Materials Science \& Engineering A, vol. 528, no. 25-26, pp. 7537-7540, 2011.
[17] K. Nakamura, K. Neishi, K. Kaneko, M. Nakagaki, and Z. Horita, "Development of severe torsion straining process for rapid continuous grain refinement," Materials Transactions, vol. 45, no. 12, pp. 3338-3342, 2004.

[18] M. Etou, S. Fukushima, T. Sasaki et al., "Super short interval multi-pass rolling process for ultrafinegrained hot strip," ISIJ International, vol. 48, no. 8, pp. 1142-1147, 2008.

[19] T. C. Lowe and R. Z. Valiev, "Investigations and applications of severe plastic deformation-introduction," Nato Science, vol. 80 , no. 80 , pp. $13-19,2000$.

[20] D. J. Alexander, "New methods for severe plastic deformation processing," Journal of Materials Engineering and Performance, vol. 16, no. 3, pp. 360-374, 2007.

[21] M. Karlík, P. Homola, and M. Slámová, "Accumulative rollbonding: first experience with a twin-roll cast AA8006 alloy," Journal of Alloys and Compounds, vol. 378, no. 1-2, pp. 322-325, 2004.

[22] M. Z. Quadir, M. Ferry, O. Al-Buhamad, and P. R. Munroe, "Shear banding and recrystallization texture development in a multilayered $\mathrm{Al}$ alloy sheet produced by accumulative roll bonding," Acta Materialia, vol. 57, no. 1, pp. 29-40, 2009.

[23] M. R. Toroghinejad, R. Jamaati, M. Hoseini, J. A. Szpunar, and J. Dutkiewicz, "Texture evolution of nanostructured aluminum/copper composite produced by the accumulative roll bonding and folding process," Metallurgical and Materials Transactions A: Physical Metallurgy and Materials Science, vol. 44, no. 3, pp. 1587-1598, 2013.

[24] G. Min, J.-M. Lee, S.-B. Kang, and H.-W. Kim, "Evolution of microstructure for multilayered $\mathrm{Al} / \mathrm{Ni}$ composites by accumulative roll bonding process," Materials Letters, vol. 60, no. 27, pp. 3255-3259, 2006.

[25] A. Mozaffari, H. Manesh, and K. Janghorban, "Evaluation of mechanical properties and structure of multilayered $\mathrm{Al} / \mathrm{Ni}$ composites produced by accumulative roll bonding (ARB) process," Journal of Alloys and Compounds, vol. 489, no. 1, pp. 103-109, 2010.

[26] R. N. Dehsorkhi, F. Qods, and M. Tajally, "Investigation on microstructure and mechanical properties of Al-Zn composite during accumulative roll bonding (ARB) process," Materials Science and Engineering A, vol. 530, no. 1, pp. 63-72, 2011.

[27] D. Yang, P. Cizek, P. Hodgson, and C. Wen, "Ultrafine equiaxedgrain $\mathrm{Ti} / \mathrm{Al}$ composite produced by accumulative roll bonding," Scripta Materialia, vol. 62, no. 5, pp. 321-324, 2010.

[28] H. P. Ng, T. Przybilla, C. Schmidt et al., "Asymmetric accumulative roll bonding of aluminium-titanium composite sheets," Materials Science and Engineering: A, vol. 576, pp. 306-315, 2013.

[29] S.-Y. Gu, H.-M. Fang, Z.-C. Zhou, and J. Du, "The evolution of microstructure and mechanical properties of $\mathrm{Ti} / \mathrm{Al}$ composite synthesized by accumulative roll-bonding," Acta Physica Sinica, vol. 61, no. 18, Article ID 186104, 2012.

[30] S. Ohsaki, S. Kato, N. Tsuji, T. Ohkubo, and K. Hono, "Bulk mechanical alloying of $\mathrm{Cu}-\mathrm{Ag}$ and $\mathrm{Cu} / \mathrm{Zr}$ two-phase microstructures by accumulative roll-bonding process," Acta Materialia, vol. 55, no. 8, pp. 2885-2895, 2007.

[31] M. Tayyebi and B. Eghbali, "Study on the microstructure and mechanical properties of multilayer $\mathrm{Cu} / \mathrm{Ni}$ composite processed by accumulative roll bonding," Materials Science and Engineering A, vol. 559, pp. 759-764, 2013.

[32] M. C. Chen, H. C. Hsieh, and W. Wu, "The evolution of microstructures and mechanical properties during accumulative roll bonding of $\mathrm{Al} / \mathrm{Mg}$ composite," Journal of Alloys and Compounds, vol. 416, no. 1-2, pp. 169-172, 2006. 
[33] H. S. Liu, B. Zhang, and G. P. Zhang, "Microstructures and mechanical properties of $\mathrm{Al} / \mathrm{Mg}$ alloy multilayered composites produced by accumulative roll bonding," Journal of Materials Science \& Technology, vol. 27, no. 1, pp. 15-21, 2011.

[34] X. P. Zhang, T. H. Yang, S. Castagne, and J. T. Wang, "Microstructure; bonding strength and thickness ratio of $\mathrm{Al} / \mathrm{Mg} / \mathrm{Al}$ alloy laminated composites prepared by hot rolling," Materials Science and Engineering A: Structural Materials Properties Microstructure And Processing, vol. 528, no. 4-5, pp. 19541960, 2011.

[35] H. Chang, M. Y. Zheng, W. M. Gan, K. Wu, E. Maawad, and H. G. Brokmeier, "Texture evolution of the Mg/Al laminated composite fabricated by the accumulative roll bonding," Scripta Materialia, vol. 61, no. 7, pp. 717-720, 2009.

[36] K. Wu, H. Chang, E. Maawad, W. M. Gan, H. G. Brokmeier, and M. Y. Zheng, "Microstructure and mechanical properties of the $\mathrm{Mg} / \mathrm{Al}$ laminated composite fabricated by accumulative roll bonding (ARB)," Materials Science and Engineering: A, vol. 527, no. 13-14, pp. 3073-3078, 2010.

[37] T. Hausöl, H. W. Höppel, and M. Göken, "Ultrafine-grained AA6014/AA5754 laminates produced by accumulative roll bonding (ARB)," Materialwissenschaft und Werkstofftechnik, vol. 43, no. 4, pp. 334-339, 2012.

[38] I. Topic, H. W. Höppel, D. Staud, M. Merklein, M. Geiger, and M. Göken, "Formability of accumulative roll bonded aluminum AA1050 and AA6016 investigated using bulge tests," Advanced Engineering Materials, vol. 10, no. 12, pp. 1101-1109, 2008.

[39] L. H. Su, C. Lu, G. Y. Deng, K. Tieu, and X. D. Sun, "Microstructure and mechanical properties of 1050/6061 laminated composite processed by accumulative roll bonding," Reviews on Advanced Materials Science, vol. 33, no. 1, pp. 33-37, 2013.

[40] L. Su, C. Lu, G. Deng, and K. Tieu, "Microstructure and mechanical properties of AA5005/AA6061 laminated composite processed by accumulative roll bonding," Metallurgical and Materials Transactions B: Process Metallurgy and Materials Processing Science, vol. 45, no. 2, pp. 515-522, 2014.

[41] L. Su, C. Lu, A. K. Tieu, G. Deng, and X. Sun, "Ultrafine grained AA1050/AA6061 composite produced by accumulative roll bonding," Materials Science and Engineering A-Structural Materials Properties Microstructure and Processing, vol. 559, pp. 345-351, 2013.

[42] S. Roy, B. R. Nataraj, S. Suwas, S. Kumar, and K. Chattopadhyay, "Microstructure and texture evolution during accumulative roll bonding of aluminium alloys AA2219/AA5086 composite laminates," Journal of Materials Science, vol. 47, no. 17, pp. 64026419, 2012.

[43] M. Talebian and M. Alizadeh, "Manufacturing Al/steel multilayered composite by accumulative roll bonding and the effects of subsequent annealing on the microstructural and mechanical characteristics," Materials Science and Engineering A, vol. 590, pp. 186-193, 2014.

[44] J. S. Carpenter, S. C. Vogel, J. E. Ledonne, D. L. Hammon, I. J. Beyerlein, and N. A. Mara, "Bulk texture evolution of $\mathrm{Cu}-\mathrm{Nb}$ nanolamellar composites during accumulative roll bonding," Acta Materialia, vol. 60, no. 4, pp. 1576-1586, 2012.

[45] J. S. Carpenter, T. Nizolek, R. J. McCabe et al., "Bulk texture evolution of nanolamellar $\mathrm{Zr}-\mathrm{Nb}$ composites processed via accumulative roll bonding," Acta Materialia, vol. 92, pp. 97-108, 2015.

[46] A. Shabani, M. R. Toroghinejad, and A. Shafyei, "Fabrication of $\mathrm{Al} / \mathrm{Ni} / \mathrm{Cu}$ composite by accumulative roll bonding and electroplating processes and investigation of its microstructure and mechanical properties," Materials Science and Engineering: A, vol. 558, pp. 386-393, 2012.

[47] K. Zhang, G.-Y. Qin, S.-Y. Xu, J.-X. Guo, and G. Ma, "Preparation of $\mathrm{Ag}-\mathrm{Ni}-\mathrm{Cu}$ composite material by ultrasonic arc spray forming and accumulative roll bonding and the evolution of its microstructure," Metallurgical and Materials Transactions APhysical Metallurgy and Materials Science, vol. 46, no. 2, pp. 880-886, 2015.

[48] Z. Chen, Q. Chen, Q. Liu, Z. Zhou, and G. Wang, "Fabrication and mechanical properties of ultrafine structured dissimilar laminated metal composite sheets (LMCS)," Science and Engineering of Composite Materials, vol. 22, no. 1, pp. 71-79, 2015.

[49] Z. Chen, X. Wu, H. Hu, Q. Chen, and Q. Liu, "Effect of individual layer shape on the mechanical properties of dissimilar al alloys laminated metal composite sheets," Journal of Materials Engineering and Performance, vol. 23, no. 3, pp. 990-1001, 2014.

[50] T. Hausöl, H. W. Höppel, and M. Göken, "Tailoring materials properties of UFG aluminium alloys by accumulative roll bonded sandwich-like sheets," Journal of Materials Science, vol. 45, no. 17, pp. 4733-4738, 2010.

[51] N. V. Govindaraj, J. G. Frydendahl, and B. Holmedal, "Layer continuity in accumulative roll bonding of dissimilar material combinations," Materials \& Design, vol. 52, pp. 905-915, 2013.

[52] Ö. Yazar, T. Ediz, and T. Öztürk, "Control of macrostructure in deformation processing of metal/metal laminates," Acta Materialia, vol. 53, no. 2, pp. 375-381, 2005.

[53] X. Gómez and J. Echeberria, "Microstructure and mechanical properties of carbon steel A210-superalloy Sanicro 28 bimetallic tubes," Materials Science and Engineering: A, vol. 348, no. 1-2, pp. 180-191, 2003.

[54] J.-M. Lee, B.-R. Lee, and S.-B. Kang, "Control of layer continuity in metallic multilayers produced by deformation synthesis method," Materials Science and Engineering A, vol. 406, no. 12, pp. 95-101, 2005.

[55] P. Paupler, "G. E. Dieter. Mechanical Metallurgy. 3rd ed., Mc Graw-Hill Book Co., New York 1986," Crystal Research and Technology, vol. 23, no. 2, p. 194, 1988.

[56] A. Misra, M. Verdier, Y. C. Lu et al., "Structure and mechanical properties of $\mathrm{Cu}-\mathrm{X}(\mathrm{X}=\mathrm{Nb}, \mathrm{Cr}, \mathrm{Ni})$ nanolayered composites," Scripta Materialia, vol. 39, no. 4-5, pp. 555-560, 1998.

[57] P. H. Shingu, K. N. Ishihara, A. Otsuki, and I. Daigo, "Nanoscaled multi-layered bulk materials manufactured by repeated pressing and rolling in the $\mathrm{Cu}-\mathrm{Fe}$ system," Materials Science and Engineering A, vol. 304, no. 1-2, pp. 399-402, 2001.

[58] A. Y. Chen, Y. K. Li, J. B. Zhang, D. Pan, and J. Lu, "The influence of interface structure on nanocrystalline deformation of a layered and nanostructured steel," Materials \& Design, vol. 47, pp. 316-322, 2013.

[59] J. Wadsworth and D. R. Lesuer, "Ancient and modern laminated composites-from the Great Pyramid of Gizeh to Y2K," Materials Characterization, vol. 45, no. 4-5, pp. 289-313, 2000.

[60] C. M. Cepeda-Jiménez, M. Pozuelo, O. A. Ruano, and F. Carreño, "Influence of the thermomechanical processing on the fracture mechanisms of high strength aluminium/pure aluminium multilayer laminate materials," Materials Science and Engineering A, vol. 490, no. 1-2, pp. 319-327, 2008.

[61] C. M. Cepeda-Jiménez, J. M. García-Infanta, M. Pozuelo, O. A. Ruano, and F. Carreño, "Impact toughness improvement of high-strength aluminium alloy by intrinsic and extrinsic fracture mechanisms via hot roll bonding," Scripta Materialia, vol. 61, no. 4, pp. 407-410, 2009. 

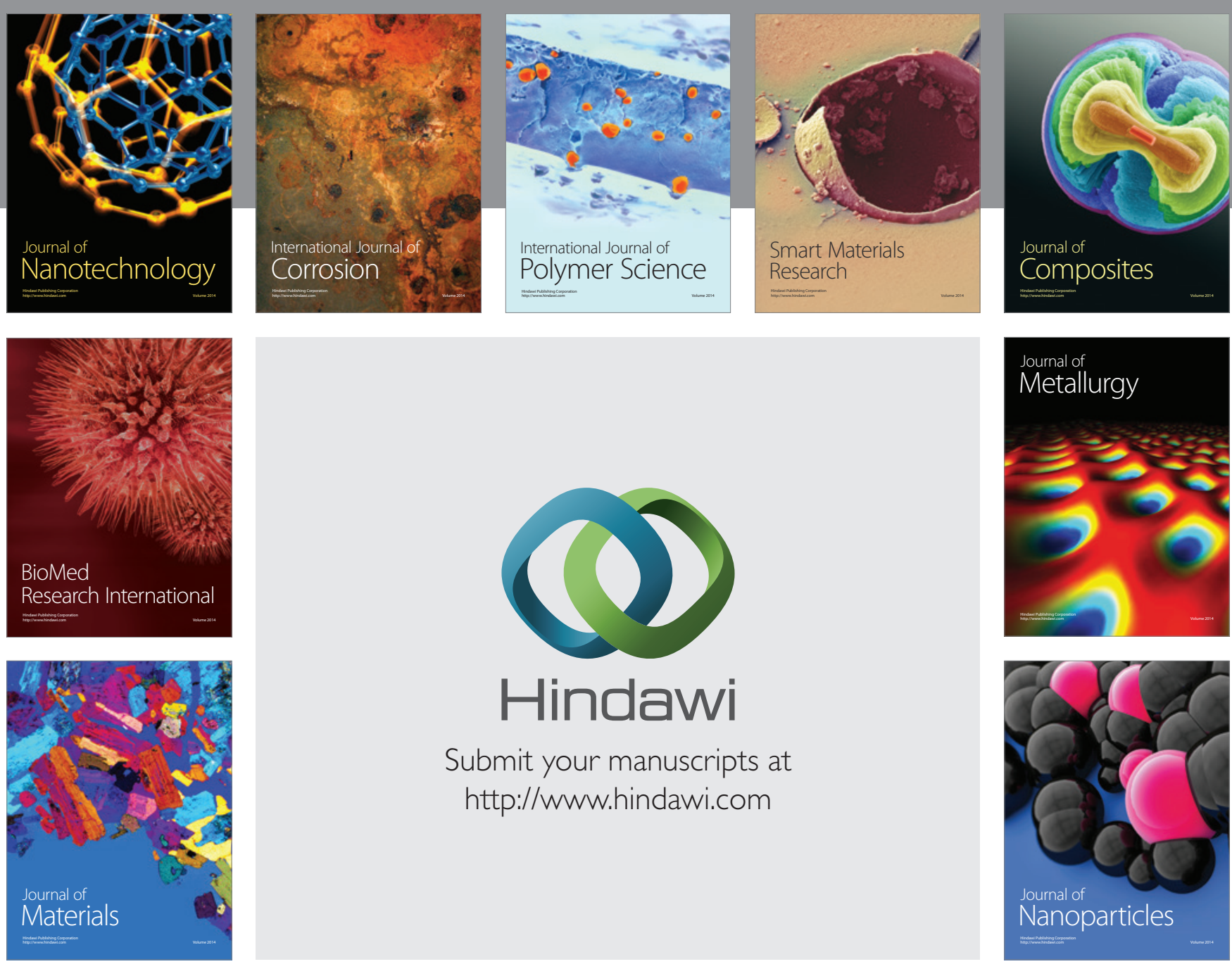

Submit your manuscripts at http://www.hindawi.com
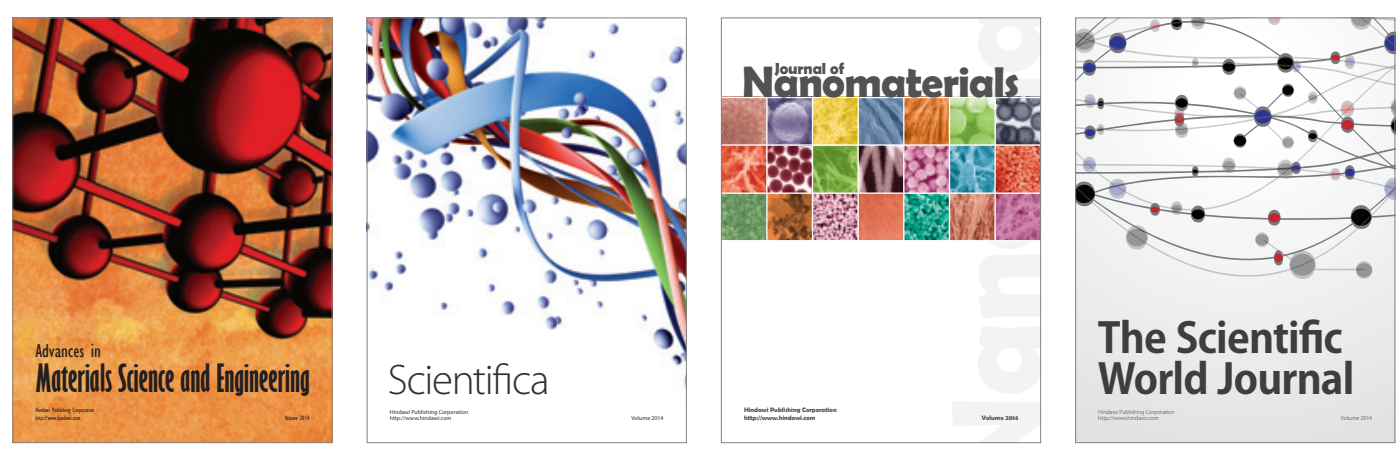

\section{The Scientific World Journal}
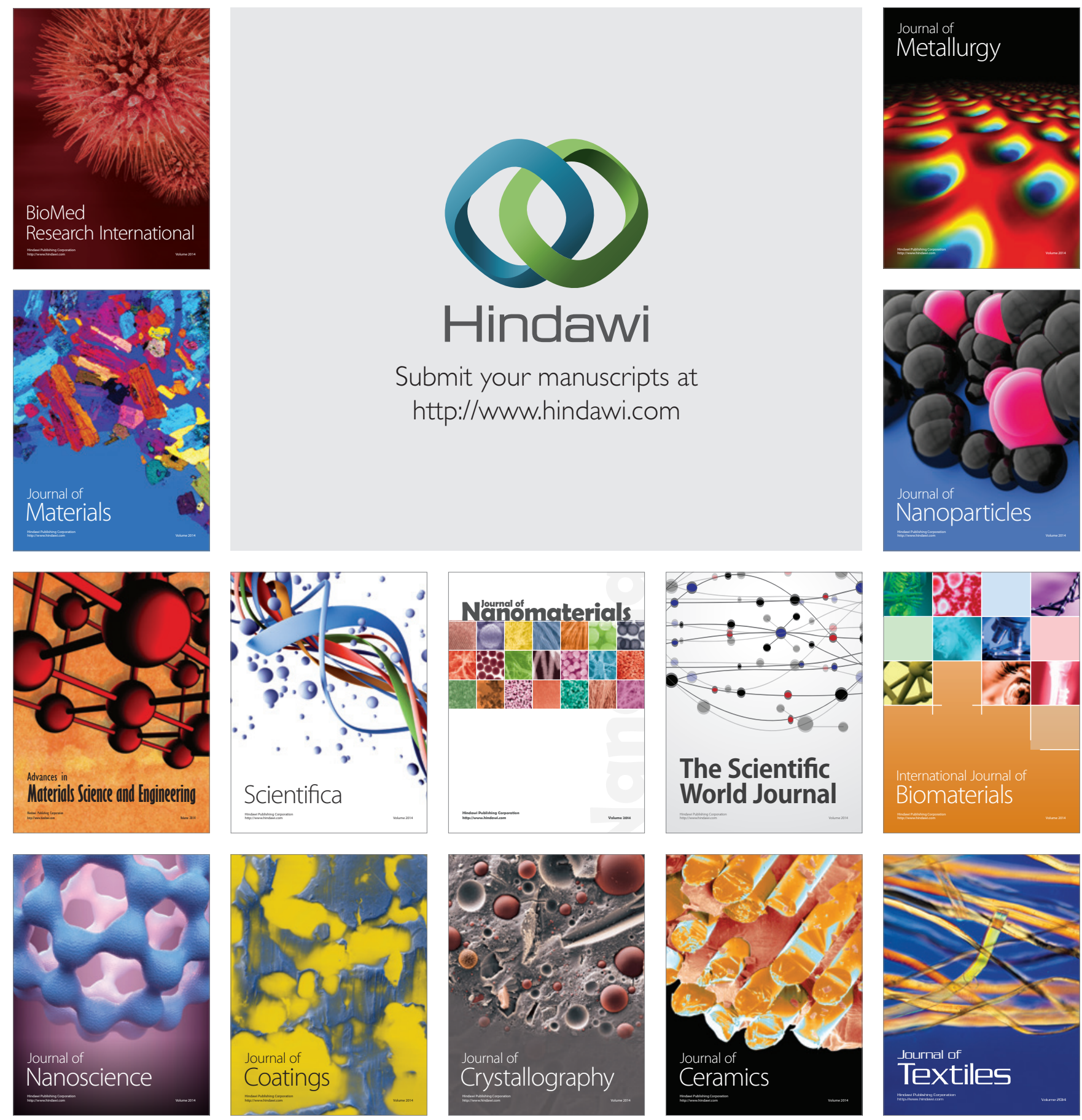